Research Article

\title{
Assessment of availability and pattern of utilization of institutional obstetric care by Venn exercises in rural Mysore, India
}

\author{
Hugara Siddalingappa ${ }^{1}$, Narayana Murthy M. R. ${ }^{1}$, Maya Mascarenhas ${ }^{2}$, $\operatorname{Varsha~Hoogar}^{1}$, \\ Sulekha $T^{3}$, Prem K Mony ${ }^{3}$
}

\author{
${ }^{1}$ Department of Community Medicine, JSS Medical College, Mysore, Karnataka, India-570015 \\ ${ }^{2}$ MYRADA, Bengaluru, Karnataka, India \\ ${ }^{3}$ Department of Community health and Epidemiology, St. John's Medical College, Bengaluru, Karnataka, India
}

Received: 02 February 2016

Revised: 05 February 2016

Accepted: 05 March 2016

\section{*Correspondence: \\ Dr. Hugara Siddalingappa, \\ E-mail: siddalingsh@yahoo.co.in}

Copyright: (c) the author(s), publisher and licensee Medip Academy. This is an open-access article distributed under the terms of the Creative Commons Attribution Non-Commercial License, which permits unrestricted non-commercial use, distribution, and reproduction in any medium, provided the original work is properly cited.

\begin{abstract}
Background: With improving indicators of maternal and child health $(\mathrm{MCH})$ the increasing expenditure of the Government on health can be substantiated. But considering the growing number of hospitals in private sector, it is desirable to understand the preference of the rural population.

Methodology: Four primary health centres (PHCs) were selected from the district by stratified random sampling based on their performance in $\mathrm{MCH}$. Accredited social health activist (ASHA), female and male health workers of selected PHC were involved in Venn exercise to explore the availability and utilization pattern.

Results: Villages nearer to district headquarter had plenty of options (hospitals) and institutions were fewer as they went away from headquarter. Maximum mothers used PHC for registration of pregnancy and basic antenatal care. Nearby community health centres (CHC), talluka and district hospitals were utilized by more than $90 \%$ mothers for intranatal care. Very few mothers preferred private hospitals for intranatal care because of high cost and unavailability of maternity benefits. In tribal PHC area, NGO hospital was preferred more than public sector due to preference of lady doctor. Cost of care was minimum with decreasing distance from district/talluka hospital. Private hospitals were charging two to three times the expenditure in public sector for the same service.

Conclusion: Delivery facility was available within 10 to $15 \mathrm{Km}$ distance of each village and government sector was the leading obstetric care provider in the study area.
\end{abstract}

Key words: Obstetric care, Venn diagram, Rural Mysore

\section{INTRODUCTION}

Since the implementation of national rural health mission (NRHM), rural healthcare has got a big boost in India. This has made a huge difference in the maternal and Child health care in our country. Many PHCs were upgraded into first referral units (FRUs; 24 X 7 obstetric care centres), untied fund was provided to PHCs and sub centres to improve the facilities. 108 ambulance scheme (free government ambulances) was started to take care of the transport problem of the patients. Introduction of ASHAs as interface workers has redefined obstetric care as they take complete charge of conceived mother till her baby is immunized. This has contributed in reducing infant and maternal mortality to the desired level. Mysore is one of the districts which have implemented NRHM and all other national programs promptly and its IMR and MMR fare well below national values. It has 135 PHCs, 25 CHCs, seven talluka hospitals, two medical college hospitals. ${ }^{1}$ 
Quantitatively facilities are impressive but from qualitative aspect, it will be interesting to know how far from the people, these government facilities are situated and how much they are preferred by the rural population. With growing number, competition of private health care providers and maternity homes in the district, it is desirable to know the preference of the mothers and possible reasons for that. Thus this study was conducted a) to study the availability of Hospitals for obstetric care of the rural mothers in Mysore; b) to study pattern of utilization of these hospitals for antenatal and intranatal care; c) to identify the possible reasons for the utilization pattern.

\section{METHODS}

Four Venn exercises were conducted in four PHCs selected from Mysore district.

Research team and reflexivity where Venn exercises were facilitated by corresponding author, who is a doctor with MD in community medicine and works as lecturer in a private medical college. Facilitator had teaching and field research experience of three years.

For sampling four PHCs were selected by stratified random sampling based on the criterion of their performance in institutional deliveries, low birth weight rate, registration of Pregnancies and implementation of a National maternity benefit program, janani suraksha yojana (JSY) representing high (Udbhuru), average (Hedthale) and low (Madapura) performing PHCs. One PHC with maximum tribal population (B Matkere) was chosen to know the preferences in tribal areas.
In the next step purposive sampling was used as the ASHAs, health worker male and female of that PHC were selected for the exercise as they interact more with the mothers in the area and know their preferences better. At the same time they would be aware of the available facilities in the area.

For sample size in the study Udbhuru, Madapure, Hedthale and B Matkere PHCs six, 10, 12 and six ASHAs, three, two and three health workers participated in the Venn exercises conducted on $14^{\text {th }} \mathrm{July}, 31^{\mathrm{st}} \mathrm{July}$, $19^{\text {th }}$ September and $21^{\text {st }}$ October respectively. All the ASHAs in the PHCs (totally 34) participated in the FGDs.

For the study setting after taking permission from the medical officer of the PHC, participants were asked to assemble in the meeting hall of respective PHC on predetermined date. In a well lit room they were made to sit in a circular manner. Facilitator explained the objectives and methodology of the study and after a small discussion about the PHC area, consent was taken for their participation in the exercise.

For participant details most of the ASHA workers were aged between 20 to 30 years and only five were aged more than 30 years. All had passed $10^{\text {th }}$ standard and few had completed Pre university certificate course.

All were employed for more than five years in their villages. Health worker females were from nursing background and most of them were employed for more than 10 to 15 years. Health worker male had passed 'health inspector' course and were working from last five to 15 years.

Table 1: Venn diagram dimensions and their codes.

\begin{tabular}{|c|c|c|}
\hline Dimension & Represented in & Indicating \\
\hline \multirow{5}{*}{$1^{\mathrm{st}}$} & Size of the circle (diameter in centimeters) & Availability of various $\mathrm{MCH}$ services \\
\hline & $5 \mathrm{~cm}$ & Only antenatal care facilities \\
\hline & $10 \mathrm{~cm}$ & Antenatal and normal labour \\
\hline & $15 \mathrm{~cm}$ & Upto LSCS facilities \\
\hline & $20 \mathrm{~cm}$ & Tertiary care for both mother and baby \\
\hline \multirow{6}{*}{$2^{\text {nd }}$} & Distance from the centre & Frequency of utilization \\
\hline & Innermost circle & More than $80 \%$ \\
\hline & Second circle & 50 to $80 \%$ \\
\hline & Third circle & Up to $25 \%$ \\
\hline & Fourth circle & Upto 5\% \\
\hline & Beyond fourth circle & Less than 5\% \\
\hline $3^{\text {rd }}$ & Thickness of the circle(number of extra circles kept) & Cost of the treatment \\
\hline \multirow{3}{*}{$4^{\text {th }}$} & Color of the circle & Type of facility \\
\hline & Red & Government \\
\hline & Violet & Private \\
\hline
\end{tabular}


The exercise was done to elicit information on; Obstetric care facilities in and around the PHC area; Obstetric care preferences or utilization pattern of these services by mothers in the PHC area; and Cost of treatment in these centres.

Facilitator initiated the exercise by explaining the materials to be used in the study and their interpretation. They were also explained about the different dimensions of the exercise and their meaning as shown in Table 1.

On a cardboard sheet kept on the floor, thermacoal circle of different sizes depicting a facility each, were kept at varying distance from the centre, as decided by the participants.

At the end of the exercise the Venn diagram was displayed on a board and interpretations were explained to the participants for their agreement and final comments. The methodology and findings of the study is reported according to COREQ checklist guidelines 5 .

\section{RESULTS}

Discussion with the field staff at the study PHCs revealed following information regarding availability and utilization of the obstetric care services by the mothers.

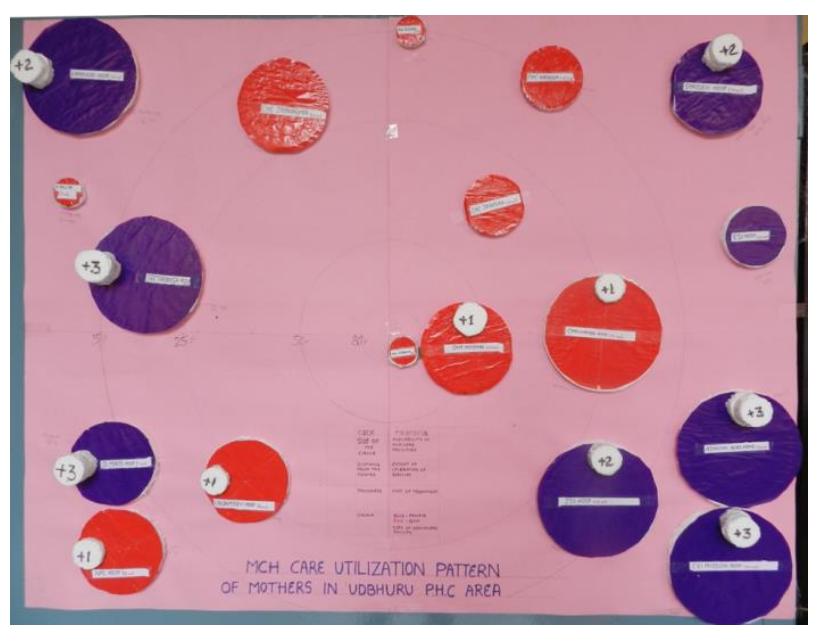

Figure 1: Venn diagram showing the availability and utilization pattern of antenatal and intranatal services in Udbhuru PHC area.

As Udbhuru was only $15 \mathrm{~km}$ from Mysore, mothers had lot of options for obstetric care. Almost all mothers had registered pregnancy at Udbhuru PHC and for normal delivery government hospital (CHC) in the city outskirts was utilized by more than $70 \%$. Few had used Cheluvamba (District) hospital as first preference (10$15 \%)$. CHC Jayapura (10km away) was another preferred place for antenatal care. As seen in Figure 1, 95\% of the mothers had preferred government facility for ante and intranatal care. Very few families had used private hospitals which included tertiary care hospitals and few nursing homes. Cost of treatment was least in
Government hospital but indirect costs made it double the PHC cost.

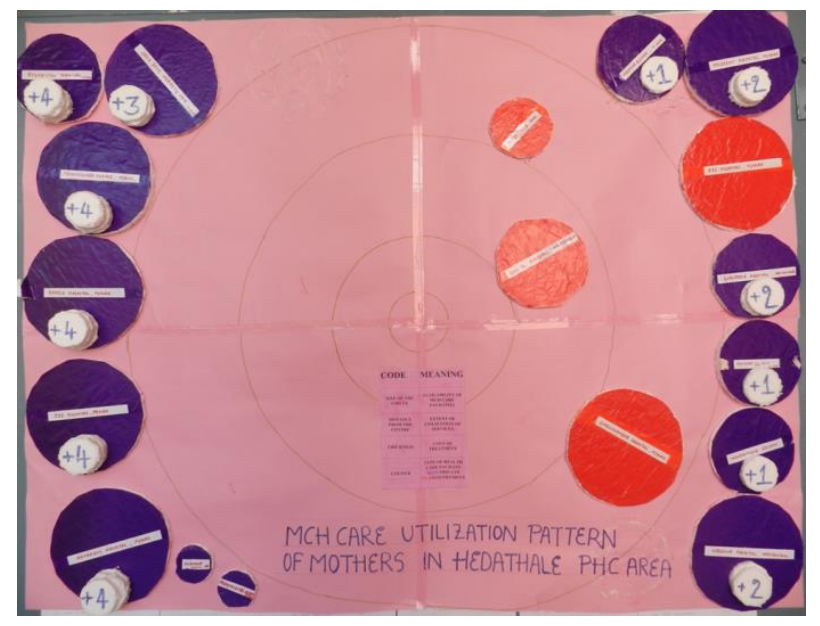

Figure 2: Venn diagram showing the availability and utilization pattern of antenatal and intranatal services in Hedthale PHC area.

Unlike Udbhuru, Hedthale PHC mothers had option of both ANC and delivery facility at their PHC. As they were close to talluka place ( 5 to $15 \mathrm{kms}$ ), there were option of nursing homes. But more than $95 \%$ had used only three hospitals.

Hedthale PHC mainly for ANC care and few normal deliveries, taluka hospital for maximum deliveries and district hospital in Mysore for complications. Cost of the treatment was less in the government hospitals excluding the monetary gifts. Very few affordable families had opted for private nursing homes in Mysore which is around 25 to $30 \mathrm{kms}$ away from these villages.

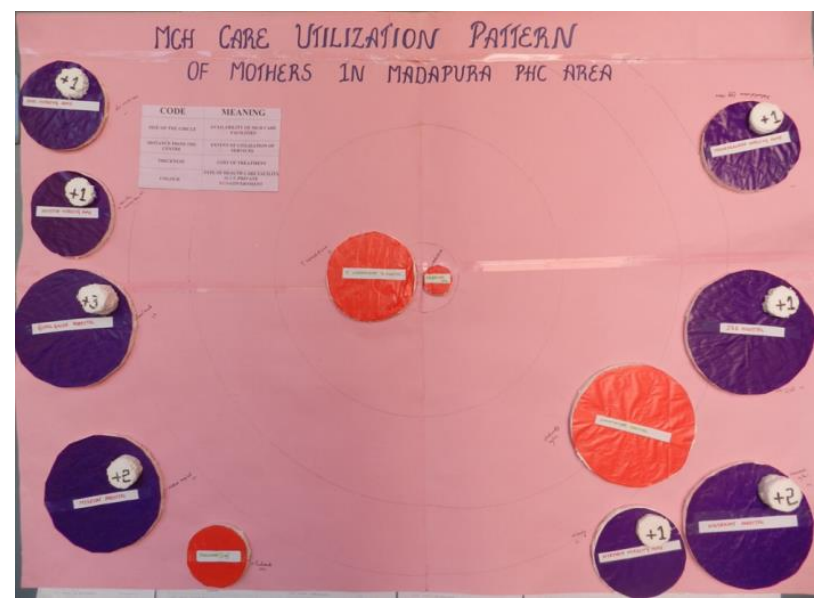

Figure 3: Venn diagram showing the availability and utilization pattern of antenatal and intranatal services in Madapura PHC area.

Madapura PHC was nearly $45 \mathrm{kms}$ away from Mysore. There were no private obstetric care providers in and around this PHC area. ANC check-ups were done at PHC 
for maximum mothers (>95\%) and many mothers preferred the Taluka Hospital for delivery which was five to10 KMs away. Very few mothers $(<10 \%)$ had come to Mysore for complicated deliveries where again district hospital was the preferred choice.

Compared to Udbhuru and Hedthale very few hospitals were utilized by mothers of Madapura. The satisfactory care for the mothers in PHC as well as Talluka hospital was the main reason for this according to ASHAs.

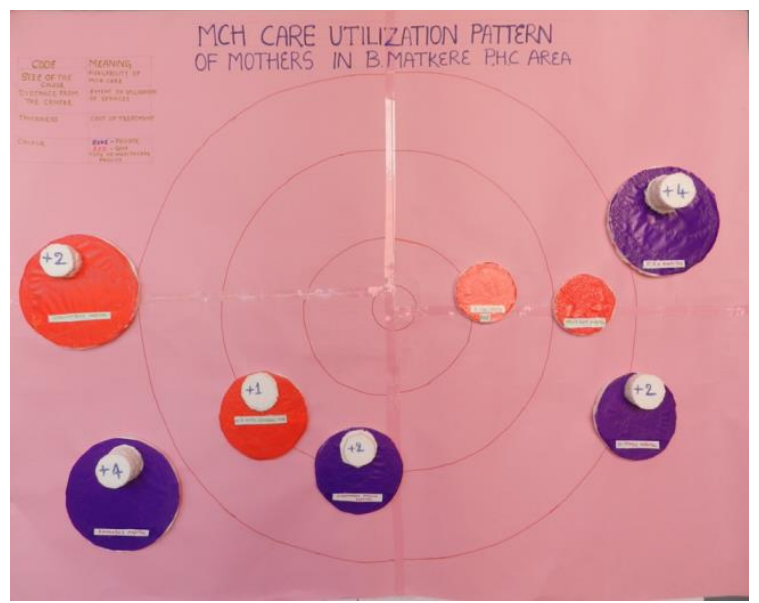

Figure 4: Venn diagram showing the availability and utilization pattern of antenatal and intranatal services in B Matkere PHC area

B Matkere (tribal PHC) had a contrasting picture where the options were very few for the mothers. This PHC was $80 \mathrm{Km}$ from Mysore. PHC was used mainly for the ANC, though it had normal delivery facilities. Unlike other PHCs, there were very few private clinics nearby, thus antenatal care was mostly taken at Govt facilities. NGO hospital was utilized by more than $50 \%$ mothers for normal delivery. Being an NGO hospital and close to the study PHC area, its cost was almost same as travelling to District hospital at Mysore. Taluka hospital was felt bit costly because of monetary gifts to be given there. Only District hospital and JSS Hospital (both are tertiary care hospitals in Mysore) were utilized by few mothers $(<5 \%)$ indicating they travelled to Mysore city only for the tertiary care.

\section{DISCUSSION}

All the villages in the study PHCs were having access to hospitals with antenatal care (ANC) facilities within 10 kms distance. Most of the times it was corresponding PHCs. Few mothers utilized the neighboring PHCs for ANC. The findings were similar to the all India value of average distance from PHC as reported by Suganthan in their NFHS study reports, which was $6.6 \mathrm{kms}$. Adequate health workers who regularly visit the eligible (married) women had motivated and helped these women to utilize government facilities. ${ }^{2}$ Increasing awareness about the maternity benefit schemes and increasing health awareness among the people were quoted as reasons by ASHAs.

For Hospital with normal labour facilities, pregnant women had to travel to the nearby CHCs or Talluka hospitals, which were around 10 to $20 \mathrm{Kms}$ away. Gynecologists working from many years in these hospitals attracted mothers towards government sector. For LSCS either district hospital of Talluka hospitals were preferred choice. District hospital of Mysore is also attached to Medical College and availability of adequate staff and postgraduates in it ensured reliable tertiary care for the mothers and newborns. People residing in villages close to district headquarters had the options of more than 15 to 20 private hospitals and nursing homes with varying cost of treatment. In the periphery hardly there were any private gynecologists or maternity homes. One NGO hospital in the tribal area was providing secondary level care including LSCS facilities.

Utilization of these hospitals was contrary to the general belief that private sector is the leading healthcare provider in India. Unlike general healthcare services, obstetric care was preferred at the government hospitals by majority. Few people went to private hospitals which were recognized by the government for the benefit schemes. As seen from all the Venn diagrams, PHC was utilized by almost all the mothers in the area for registration of pregnancy and initial few visits. Government Medical College hospital (Cheluvamba hospital) was the most preferred hospital for many mothers. Though delivery facilities were available at a distance of less than 10-15 Kms in the form of FRUs, Talluka and district hospitals were preferred for their advanced neonatal care and ability to handle complications.

It was encouraging to see the Government services being utilized by most of the mothers in the study area. Availability of good services at the district and sub district Government hospitals along with maternity benefit schemes was the main reason rather than low cost. In non-tribal PHCs ASHAs and ANMs opined that more than $99 \%$ of the deliveries happen at hospitals. In the present study area, institutional delivery rate was 93 to $95 \%$ in $2009-10{ }^{3}$ In tribal hamlets the scenario was different. Though the trend of home delivery is regressing, still 5 to $10 \%$ of the tribal women give birth to babies in their homes with the assistance of untrained dais. Mysore's institutional delivery rate in 2012-13 being $95.2 \%$ (DLHS-4), ${ }^{4}$ IMR and MMR being15.6 per 1000 and 34.5 per 100000 live births respectively, stands seventh in the state in composite health index rating by National Commission on Population with a score of $76 .{ }^{5}$ Despite these claims by the government; there were some independent studies which reported otherwise in tribal areas of Mysore, with only $66 \%$ of the mothers were living in vehicle accessible hamlets and $41 \%$ deliveries at home (SVYM, 2009). ${ }^{6}$ Another study done by Kavita Yadav (yet to be published) in 2013-14 revealed $21 \%$ 
home deliveries among the tribal hamlets. ${ }^{7}$ ASHAs in the study area opined that distance from the hospital was not a problem but, the awareness of tribal mothers regarding institutional delivery should be increased to stop home deliveries. This view is supported by the findings from Suganthan who dint finds any association between distance and place of delivery even a decade ago. ${ }^{2}$

The range of hospitals utilized, especially private facilities decreased as the distance increased from the headquarters. In areas close to Mysore city also the private hospitals were sparsely used owing to their cost of treatment which was more than double the cost in government facilities. Charges of normal labour in some nursing homes were four to five times more than all direct and indirect expenditure of hospitalization for labour in government hospitals.

Two study PHCs were having normal delivery facilities. Still they were largely used only for antenatal care as one was lacking full time doctor and the other was in tribal area where a male doctor was appointed and mothers preferred lady doctor in a distant NGO hospital.

\section{CONCLUSION}

Physical infrastructure needed for the obstetric care has been set up in the rural Mysore, which is easily accessible and affordable. More than $90 \%$ of the mothers in the study areas had preferred government hospitals for obstetric care. Implementation of various maternity benefit schemes has been an added advantage for the government sector, which is ensuring their maximum utilization by mothers.

Funding: This work was made possible by the Maternal Health Task Force at the Harvard T. H. Chan School of Public Health through Grant \#01065000621 from the Bill \& Melinda Gates Foundation. The Maternal Health Young Professionals (India) Mentoring Program was based at St John's Medical College \& Research Institute, Bangalore.
Conflict of interest: None declared

Ethical approval: The study was approved by the Institutional Ethics Committee

\section{REFERENCES}

1. Mysore.pdf [2014 Nov 1]. Available from: https://nrhm-mis.nic.in/ DLHS4/ Karnataka/ District\%20Factsheets/Mysore.pdf.

2. Suganthan KS, Mishra V, Rutherford RD. Promoting institutional deliveries in rural India. National family health survey study reports, 2001. [cited on 20-1-2016] available at; http://www.eastwestcenter.org/ sites/ default/ files/ filemanager/Research_Program/NFHS_Subject_Rep orts/ subj-20.pdf

3. Jayashree GR. knowledge on janani suraksha yojana among antenatal mothers. Hassan, Karnataka. RGUHS. 2013.

4. Ministry of health and family welfare, government of India. district level household and family survey - 4. Pdf. Available from: http://rchiips.org/ pdf/ dlhs4/ report/ KA.pdf,.

5. MOHFW. Mysore.pdf [Internet]. [cited 2014 Nov 1]. Available from: https://nrhm-mis.nic.in/ DLHS4/ Karnataka/ District\%20Factsheets/Mysore.pdf

6. svym_-_brief_29-09-12_final_for_print.pdf [Internet]. [cited 2014 Nov 1]. Available from: http://www.chsj.org/uploads/1/0/2/1/10215849/svy m_-_brief_29-09-12_final_for_print.pdf.

7. Yadav K. Factors affecting choice of place of delivery among tribal mothers in HD Kote taluk Mysore. MPH dissertation. JSS Medical College, Mysore. 2015.

Cite this article as: Siddalingappa H, Murthy NMR, Mascarenhas M, Hoogar V, Sulekha T, Mony PK.

Assessment of availability and pattern of utilization of Institutional obstetric care by Venn exercises in rural Mysore, India. Int J Community Med Public Health 2016;3:1038-42. 